\title{
Study of the mortality and exploitation parameters of Sander lucioperca (Linnaeus, 1758) in the Al Massira Reservoir
}

\author{
Meriem BOUSSEBA ${ }^{I^{*}}$, Loubna FERRAJ ${ }^{1}$, Sara OUAHB $^{1}$, Mohammed DROUSSI ${ }^{2}$ and Mustapha HASNAOUI ${ }^{1}$ \\ ${ }^{1}$ Environmental Engineering Team, Sciences and Techniques Faculty, Sultan Moulay Slimane University, Beni-Mellal, \\ Morocco \\ ${ }^{2}$ International expert in aquaculture, Morocco \\ *Email: meriembousseba@gmail.com
}

\begin{abstract}
The mortality parameters and exploitation of Sander lucioperca were studied for the first time in the reservoir of Al-Massira Dam. These parameters were estimated based on sizefrequency data processed by FISAT II software. Parameters such as total mortality (Z), natural mortality $(\mathrm{M})$, fishing mortality $(\mathrm{F})$, and exploitation rate $(\mathrm{E})$ obtained are respectively 1.71 year${ }^{1} ; 0.42$ year $^{-1} ; 1.29$ year $^{-1}$ and 0.75 . This study thus shows that this species undergoes fishing mortality $\left(1.29\right.$ year $\left.^{-1}\right)$ much higher than natural mortality $\left(\mathrm{M}=0.42\right.$ year $\left.^{-1}\right)$. Furthermore, Sander lucioperca is found in a state of overexploitation with an exploitation rate $(\mathrm{E}=0.75)$ higher than the estimated maximum exploitation rate $(\operatorname{Emax}=0.65)$.
\end{abstract}

Keywords: Sander lucioperca, Al-Massira Dam, Mortality, Exploitation.

\section{Introduction}

The genus Sander lucioperca belongs to the Percidae family, which is composed of 159 species and nine genera. This fish is found exclusively in freshwater, even brackish [1]. The pike perch, less demanding in terms of reproduction, has thrived widely, including in highly anthropized environments. It now represents an important fishery resource, particularly in Moroccan freshwater, where it has experienced real development.

The pike perch is now one of the predators most sought after by amateur fishermen [1] and presents an essential commercial resource. It is therefore under intense exploitation pressure and may be threatened by overfishing, and therefore, an assessment of the stock status is necessary to ensure the sustainability of its exploitation. Indeed, fishing pressure is considered the main cause of the decline in the abundance of fisheries resources and represents the greatest threat to the sustainable development of fishing activity. According to FAO estimates in 2016 [2], about $31.4 \%$ of fish stocks are overexploited, $58.1 \%$ are fully exploited and only $10.6 \%$ are underexploited.

To date, no study on the exploitation parameters of Sander lucioperca is available in Morocco. This study aims is to estimate the parameters of mortality and exploitation of Sander lucioperca at Al-Massira Dam with a view to rational management and sustainable exploitation of the stocks of this species.

\section{Materials and methods}

The Al Massira Dam $\left(31^{\circ} 900^{\prime} \mathrm{N}\right.$ and $\left.6^{\circ} 72^{\prime} \mathrm{W}\right)$ is located at an altitude of $385 \mathrm{~m}$ on the Oued Oum Er Rabia. It extends over a length of $30 \mathrm{~km}$, and its maximum width is $10 \mathrm{~km}$. It is characterized by a maximum depth of $40 \mathrm{~m}$, a water surface of $139 \mathrm{~km}^{2}$ and a capacity of 2760 million $\mathrm{m}^{3}$. The Al Massira reservoir does not show a strong thermal stratification during the summer, because its waters are well mixed under the effect of the wind and/or restitution. As a result, only a weak thermal gradient is observed during this summer period.

The lake's watershed, with an area of $28.500 \mathrm{~km}^{2}$, is subject to a predominantly semi-arid Mediterranean climate and is characterized by the heterogeneity of the land crossed by the Oued Oum Er Rabia (from the Paleozoic to the Quaternary). The reservoir is intended to strengthen the production of energy and the supply of drinking water and develop the irrigation of the surrounding areas.

The used data in the present study come from the sampling carried out monthly during the period March 2019 and February 2020. The specimens studied are captured in the Dam Lake Al-Massira. The total length (Lt) was measured for each fish, which allowed us to establish the sample sizefrequency distribution. The measurements will subsequently be used to study mortality and exploitation. 
The ELEFAN I (Electronic Size Frequency Analysis) routine of the FiSAT II program [8], was used to estimate the population parameters.

\section{1 Estimation of the different Sander Iucioperca mortality coefficients}

\subsubsection{Estimation of the total mortality coefficient (Z)}

Different approaches allow the estimation of the total mortality coefficient $Z$. As far as we are concerned, we have used the following methods:

- Powell (1979)-Wetherall (1986) method [3] [4]: The Powell-Wetherall method allows the estimation of $\mathrm{Z} / \mathrm{K}$ from the sizefrequencies.; knowing $\mathrm{K}$, the total mortality coefficient $Z$ is then determined:

$$
Z / K=b /(1-b)
$$

- Pauly method (1984) [5]: This method is based on the capture curve, using length data converted to age from the Von Bertalanffy equation.

- Method of Beverton and Holt (1956) [6]: Beverton and Holt have shown a relationship between the instantaneous total mortality coefficient $Z$ and length or age: Thus, $Z$ can be estimated from the equation:

$$
Z=K\left(L \infty-L_{m o y}\right) /\left(\text { Lmoy } \boldsymbol{L}^{\prime}\right)
$$

$\mathrm{L} \infty$ and $\mathrm{K}$ are the growth parameters of Von Bertalanffy, Lmoy: the average length of the processed fish in the frequency distribution, L ': the minimum length of the processed fish in the frequency distribution or most minor class limit.

- The Jones and Van Zalingue method (1981) [7]: The Jones and Van Zalingue cumulative curve is a preliminary of the capture curve so that these two methods share several common assumptions. The determination of the total mortality is carried out from the size-frequency distribution, by plotting the line of the cumulative numbers. The slope is equal to $\mathrm{Z} / \mathrm{K}$, knowing $\mathrm{K}, \mathrm{Z}$ is determined. The equation is written:

$$
\operatorname{Ln}(\mathrm{C}(\mathrm{Li}, \mathrm{L} \infty))=\mathrm{a}+\mathrm{Z} / \mathrm{K} \operatorname{Ln}(\mathrm{L} \infty-\mathrm{Li})
$$

Where: $\mathrm{C}(\mathrm{Li}, \mathrm{L} \infty)$ : cumulative catches whose size is between a given length ( $\mathrm{Li}$ ) and the asymptotic length, $\mathrm{Li}$ : Lower limit of the size class (i), Z: Total mortality coefficient.

\subsubsection{Estimation of the coefficient of natural mortality (M)}

Natural mortality (M) is the most difficult parameter to assess in fish stock studies [8]. Several methods based on empirical equations can be used for the evaluation of natural mortality (M). In our study, we used the method of [9], as well as that of [10] which take into account the growth parameters of the species studied and the average temperature of the waters frequented by the fish at the time of their capture.

Taylor's equation (1960) [9]:

$$
M=2.996 K /\left(2.996+K t_{0}\right)
$$

The Pauly equation (1980) [10] used for the determination of $\mathrm{M}$ is:

$$
\begin{gathered}
\log M=-0.0066-0.279 \log (L \infty)+0.6543 \log \\
(K)+0.4634 \log \left(T^{\circ}\right)
\end{gathered}
$$

Where: Lo: the asymptotic total length expressed in centimeters, $\mathrm{K}$ : growth parameter (an1), $\mathrm{T}^{\circ}$ : average annual temperature of the medium in degrees Celsius

\subsubsection{Estimation of the coefficient of Fishing mortality $(F)$}

Fishing mortality is an essential parameter for studying the dynamics of an exploited stock; it is the essential parameter of exploitation [11]. This mortality expresses the quantity of fish taken by the fishing activity in a year. After having calculated the coefficients $Z$ and $M$, the determination of the fishing mortality $(\mathrm{F})$ is made from the following relation:

$$
Z=M+F \quad(6) \text { where: } F=Z-M
$$

\subsection{Estimation of the different Sander Iucioperca exploitation parameters}

\subsection{Exploitation rate (E)}

The exploitation rate $\mathrm{E}$ [13] is the ratio of individuals killed by fishing to the number of individuals dead by various causes. It is determined by the following formula:

$$
E=F / Z=F /(M+F)
$$

The stock is in equilibrium when $\mathrm{E}$ is close to 0.5 . It is based on the assumption that the potential catch is optimized when there is equality between natural mortality and fishing mortality [12] [13]: $\mathrm{E}<0.5$ : Underexploited stock; E $>0.5$ : Stock overexploited; and $\mathrm{E}=0.5$ : Stock in equilibrium; ideal situation insofar as production is maximum while ensuring the sustainability of the activity and the species.

\subsubsection{Probability of capture}

The capture probability is obtained from the ascending points located to the left of the capture curve for each size class [14]. This method made it possible to determine the selectivity parameters, including the size for which the probability of capture is $50 \%$ of the total catch (Lc or L 50) [15]. 


\subsubsection{Yields and biomasses per recruit}

The relative yield per recruit is expressed by the Beverton and Holt model [6]. It allows the relationship between yield and fishing effort to be determined by the different sizes of the first catch. This model uses the lengths [16]. The expression for Y'/R uses all three parameters: M/K, Lc /L $\infty$ and $\mathrm{E}$ :

$$
\begin{gathered}
\boldsymbol{Y}^{\prime} / \boldsymbol{R}=\boldsymbol{E U} \boldsymbol{M} / \boldsymbol{K}[\mathbf{1}-\mathbf{3 U} /(\mathbf{1}+\boldsymbol{m})+\mathbf{3 U} \mathbf{2} /(\mathbf{1} \\
+\mathbf{2 m})-\boldsymbol{U} \mathbf{3} /(\mathbf{1}+\mathbf{3 m})](9) \\
\text { With: } \quad \boldsymbol{m}=\mathbf{1}-\boldsymbol{E} /(\boldsymbol{M} / \boldsymbol{K}) \text { and } \boldsymbol{U}=\mathbf{1}-(\boldsymbol{L c} / \\
\boldsymbol{L} \infty)(10)
\end{gathered}
$$

The evaluation of the relative biomass yield per recruit:

$$
\left(B^{\prime} / R\right)=\left(Y^{\prime} / R\right) * F
$$

The curves of relative yield $\left(\mathrm{Y}^{\prime} / \mathrm{R}\right)$ and relative biomass per recruit $\left(\mathrm{B}^{\prime} / \mathrm{R}\right)$ for fixed values of $\mathrm{Lc} /$ $\mathrm{L} \infty$ and $M / K$ allowed the determination of the biological reference points of [6] for optimal management of the Sander lucioperca population studied. These biological reference points (Emax; E0.1 and E0.5) correspond respectively to the exploitation rate producing the maximum productive yield (Emax), the exploitation rate for an increase in $\mathrm{Y}^{\prime} / \mathrm{R}$ of one tenth compared to $\mathrm{E}=0$ (E0.1) and the value of $E$ for which the stock has been reduced to half its virgin biomass (E0.5).

\section{Results}

The value of the total mortality coefficient (Z) of the whole population was estimated using FISAT II software (2005) from the size-frequency distribution by different methods. The results obtained are summarized in Table 1. Figure 1 ( $a$ and $b$ ) illustrates the determination of the mortality coefficient $\mathrm{Z}$ respectively from the linear capture curve [5] and that of [7].

Furthermore, using the approximate method of [6], the estimated total mortality coefficient $\mathrm{Z}$ is 0.518 year $^{-1}$. Overall, the values for the total mortality coefficient differ from one method to another. According to the recommendations of [16], observations are excluded, from the regression of the linearized catch curve. The first size classes which form the ascending part of the curve correspond to fish which are not yet fully recruited for the fishery. The largest size classes are also excluded, for their small size and the uncertainty of the relationship between age and length as one approaches $L \infty$.

Coefficient of natural mortality (M) from the growth parameters defined previously and an average temperature of $20^{\circ} \mathrm{C}$, we evaluated the natural mortality $(\mathrm{M})$ in pike perch. For this, we used two methods which gave us two different results: Taylor [9] and Pauly [10]. Thus, the value of $\mathrm{M}$ estimated by the Taylor's method [9] gives a coefficient of 0.21 year $^{-1}$, this value doubles when we apply the Pauly equation [10] $\mathrm{M}=0.42$ year $^{-1}$.

The parameters retained for applying the exploitation models are as follows: for the total mortality coefficient $\mathrm{Z}$, we have retained the results obtained by the linear catch curve of Pauly [5].

The value retained for the natural mortality (M) is that calculated by the equation of Pauly [10], which is more adapted to the stock of pelagic fish. Thus, the values of the total $(\mathrm{Z})$ and natural $(\mathrm{M})$ mortality coefficients of Sander lucioperca are respectively equal to 1.71 year $^{-1}$ and 0.42 year $^{-1}$.

The fishing mortality coefficient $(\mathrm{F})$ calculated from the values of total $(\mathrm{Z})$ and natural $(\mathrm{M})$ mortalities is 1.29 year $^{-1}$. This result shows that fishing mortality is much higher than natural mortality. The value of the exploitation rate $\mathrm{E}$ calculated for both sexes is 0.75 .

Figure 2 illustrates the selectivity curve showing the variation in the probability of capture as a function of the sizes of Sander lucioperca. The calculated average size of the first capture (Lc or L50) is $19.77 \mathrm{~cm}$. This size corresponds to which $50 \%$ of individuals are caught by fishing gear while

Table 1. Estimation of total mortality coefficients $(Z)$ year-1 $^{-1}$ by different methods

\begin{tabular}{|c|c|c|c|c|}
\hline Methods & $\begin{array}{c}\text { Powell- } \\
\text { Wetherall }\end{array}$ & $\begin{array}{c}\text { Linear } \\
\text { growth curve }\end{array}$ & $\begin{array}{c}\text { Jones and } \\
\text { Van Zalinge }\end{array}$ & $\begin{array}{c}\text { Beverton and } \\
\text { Holt }\end{array}$ \\
\hline Sexes combined & 0.69 & 1.71 & 2.84 & 0.518 \\
\hline
\end{tabular}


(a)

\section{Length-Converted Catch Curve}

(for $Z=1.71 ; M\left(\right.$ at $\left.20.0^{\circ} \mathrm{C}\right)=0.66 ; F=1.05 ; E=0.61$ )

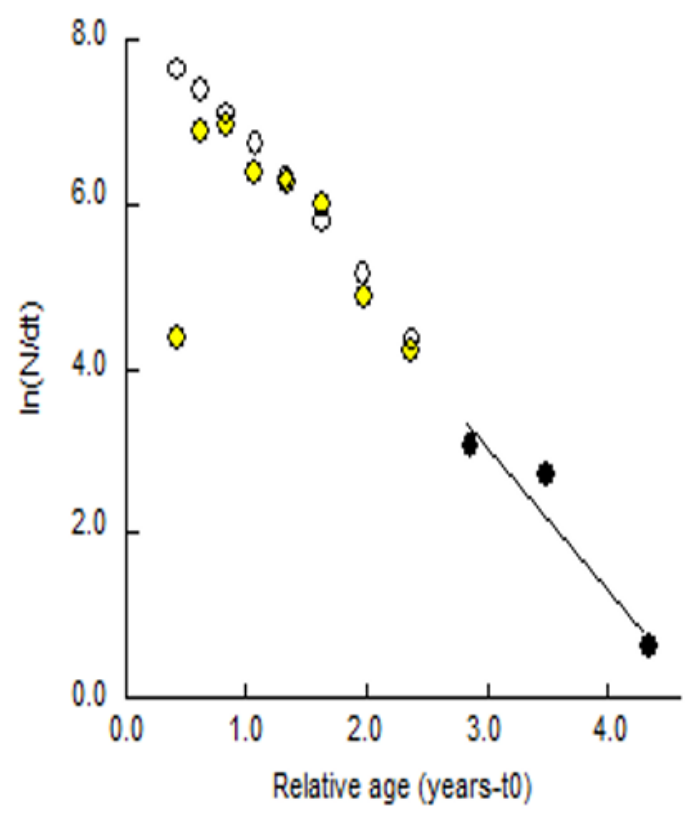

(b)

\section{Jones and van Zalinge Plot}

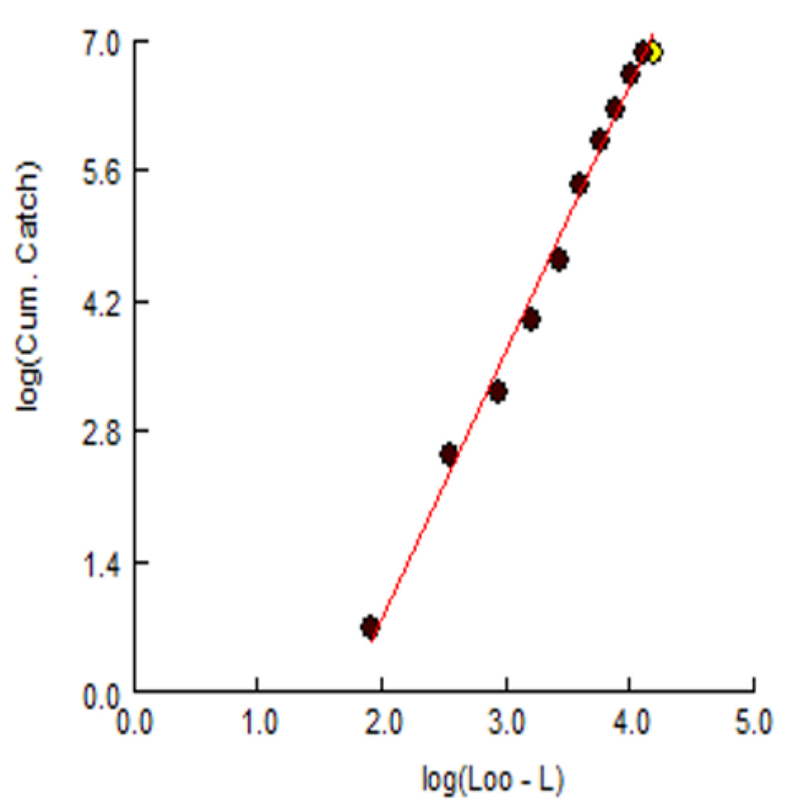

Fig 1. Determination of $Z$ from the linearised capture curve (a) and by the Jones Van Zalinge method (b).

$50 \%$ escape this capture. The sizes at which $25 \%$ and $75 \%$ of individuals are captured are respectively $11.90 \mathrm{~cm}$ and $27.64 \mathrm{~cm}$ (Table 2).

Table 2. First capture sizes (Lc).

\begin{tabular}{|l|r|r|r|}
\hline Size $(\mathrm{cm})$ & Lc 25 & Lc 50 & Lc 75 \\
\hline $\begin{array}{l}\text { Sexes } \\
\text { combined }\end{array}$ & 11.90 & 19.77 & 27.64 \\
\hline
\end{tabular}

The relative production per recruit model used is based on the model of Beverton and Holt [6] modified by Pauly and Soriono [17]. The curves of the relative biomass per recruit $\mathrm{B}^{\prime} / \mathrm{R}$ and the relative yield per recruit $Y^{\prime} / R$ expressed as a function of the exploitation rate (E) made it possible to estimate the maximum exploitation rate (Emax), which is equal to 0.65 , the exploitation rate for an increase in $\mathrm{Y}^{\prime} / \mathrm{R}$ of $10 \%(\mathrm{E} 10)$, which is equal to 0.29 and E0.5, the value of $E$ for which the stock has been reduced to half its virgin biomass, which is equal to 0.42 (Fig. $3)$.

Thus, the species presents an exploitation rate $(\mathrm{E}$ $=0.75)$ higher than the maximum exploitation rate $($ Emax $=0.65)$. The relative biomass curve gradually decreases with increasing exploitation level.

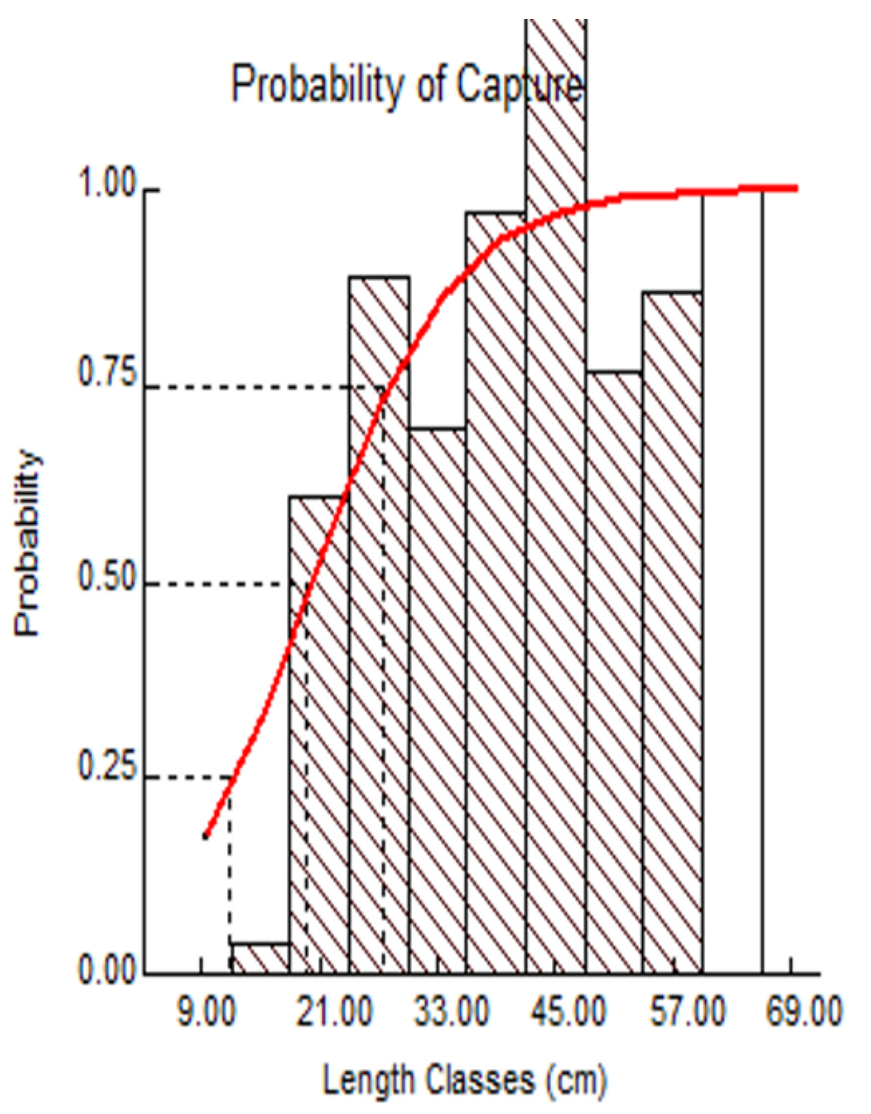

Fig 2. Selectivity curve showing the probability of capture for each size class of Sander lucioperca 

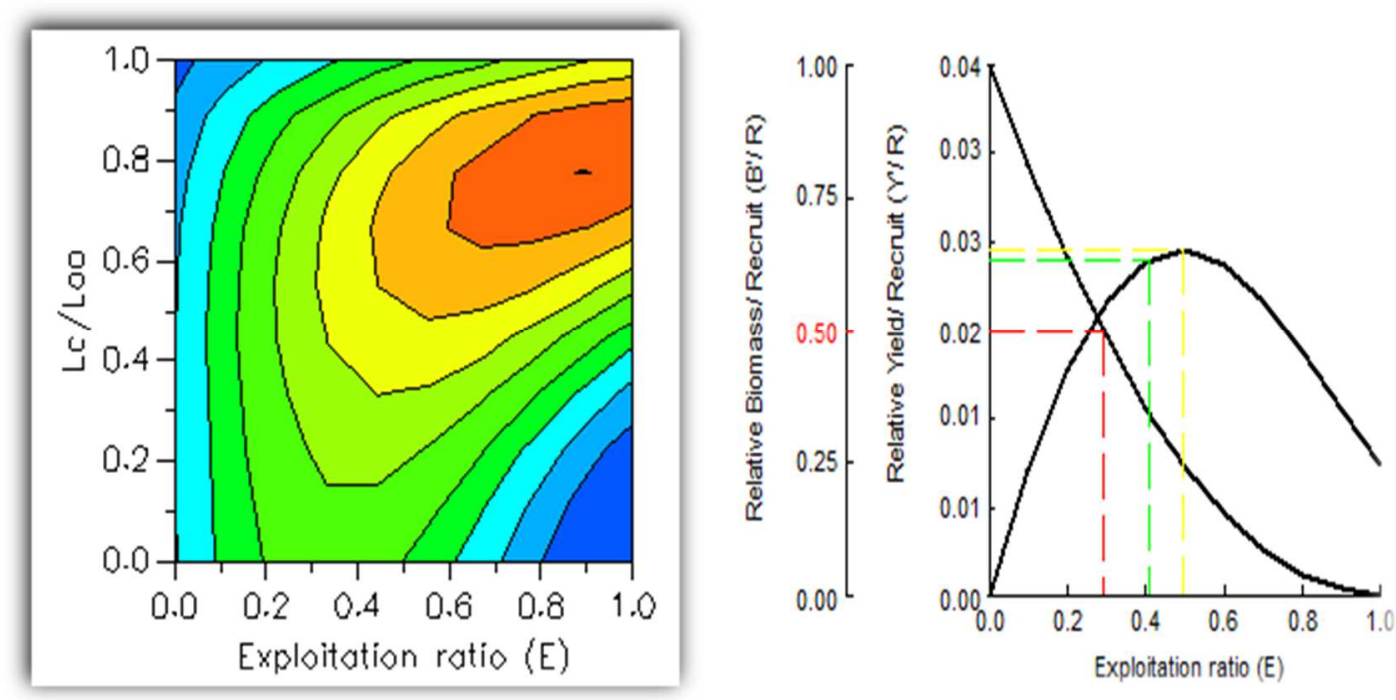

Fig 3. 3D and 2D representations of the relative production model per recruit based on knife-edge selection.

\section{Discussion}

In this study, mortality coefficients were estimated using FISAT II software, based on the size-frequency distributions of Sander lucioperca.

The natural mortality of Sander lucioperca is equal to 0.42 year $^{-1}$, which is almost similar to the results of [18] at the Sidi Salem dam in Tunisia, of [19] in three Algerian lake systems and of [20] in Lake Karataş in Turkey. On the other hand, [21] found it to 0.31 in the Caspian Sea in Iran, [22] to 0.22 at the Ghrib Dam in Algeria, [23] to 0.1 in the Baltic sea in Finland. From these results, we find that the instantaneous coefficient of natural mortality differs from one author to another and from one region to another, this amounts to the divergence of the parameters used for its determination. Several factors are associated with natural mortality, including predation, disease, stress, lack of food, ageing and pollution [24]. Natural mortality, therefore, represents any source of mortality unrelated to fishing.

For The value of the fishing mortality rate found at our study site $(F=1.29)$, it is greater than that reported for other populations of pike perch: it is equal to 1.085 in Lake Egidir (Turkey) [25], to 0.56 in a southern Baltic lagoon (Germany) [26], the value of $F$ varies between 0.5 and 0.1 in Baltic Sea (Finland) [27] [23], and to 0.71 at Lake Peipsi (Russia) [28]. Except for sander from the three Algerian lake systems, which is 1.55 (Algeria) [19] and from Karataş Lake, whose value of $\mathrm{F}$ is equal to 1.77 (Turkey) [20].
Based on our results, we notice that the fishing mortality $(F=1.29)$ is relatively high and generally higher than the natural mortality $(\mathrm{M}=0.42)$, reflecting an intensive exploitation of the species in the Al-Massira Dam. This intense fishing mortality suffered by Sander lucioperca is thought to be due to a strong fishing pressure exerted on this species because of its high commercial value. It is therefore found to be highly researched and more targeted by exploitation.

Generally, the value of the exploitation rate found in the species $(E=0.75)$ is greater than that of the maximum exploitation rate $(\operatorname{Emax}=0.65)$. In addition, the exploitation rate of Sander lucioperca at Al-Massira Dam $(E=0.75)$ is higher than the optimum reference rate defined by [12] (E0.5) = 0.29 , indicating an overexploitation of the stock of this species at this lake. This result is confirmed by the $\mathrm{Z} / \mathrm{K}$ ratio (3.141). Indeed, according to [29] cited by [30], if $Z / K<1$, this reflects the predominance of growth on the mortality in a fish population. When $\mathrm{Z} / \mathrm{K}=1$, the population is in equilibrium (mortality in equilibrium with growth). On the other hand, when in a population of fish $\mathrm{Z} / \mathrm{K}>2$, mortality predominates, and it is therefore overexploited, which is in agreement with our results $(\mathrm{Z} / \mathrm{K}=3.141>$ $2)$. These results are comparable to those of [31], [19] and [20].

The size of the first capture (Lc) of Sander lucioperca in this present study is estimated at 19.77 $\mathrm{cm}$. Moreover, the capture size obtained is greater 
than that estimated by [31] which is equal to $30 \mathrm{~cm}$. Indeed, [31] and [32] have confirmed that it is necessary to limit the minimum regulatory size for pike perch fishery to $30 \mathrm{~cm}$, which represents the maximum catch size and the size at which all individuals are adults.

\section{Conclusion}

This study revealed that the Sander lucioperca species is in a state of overexploitation with an exploitation rate higher than the maximum exploitation rate estimated at the Al-Massira Dam. Moreover, this fish suffers from fishing mortality much higher than natural mortality. In view of these different results, we recommend that rigorous management measures be taken to avoid the collapse of stocks and for a sustainable recovery of Sander lucioperca populations. These measures must focus on raising awareness of the misuse of catching gear and regulating the mesh size of the nets.

\section{References}

[1] N. Poulet, Le sandre (Sander lucioperca (L. )): biologie, comportement et dynamique des populations en Camargue (Bouches du Rhône, France), Thèse de doctorat, Toulouse 3, (2004).

[2] La situation mondiale de l'alimentation et de l'agriculture : changement climatique, agriculture et sécurité alimentaire. Rome (I): FAO, (2016).

[3] E. R. Powell, Estimation of mortality and growth parameters from the length frequency of a catch [model], Arthur Rylah Inst. for Environmental Research, Heidelberg (Australia), (1979).

[4] J. A. Wetherall, A new method for estimating growth and mortality parameters from length-frequency data, Fishbyte, vol. 4, no. 1, pp. 12-14, (1986).

[5] D. Pauly, Length-converted catch curves: a powerful tool for fisheries research in the Tropics (III: conclusion), Fishbyte, (1984).

[6] R. J. H. Beverton, A review of methods for estimating mortality rates in fish populations, with special reference to sources of bias in catch sampling, Rapp Proces-Verb Reun Cons Int Explor Mer, vol. 140, pp. 67-83, (1956).

[7] R. Jones and N. P. Van Zalinge, Estimates of mortality rate and population size for shrimp in Kuwait waters, Kuwait Bull Mar Sci, vol. 2, pp. 273288, (1981).

[8] F. C. Gayanilo, P. Sparre, and D. Pauly, FAO-ICLARM stock assessment tools II: User's guide. Food \& Agriculture Org., (2005).
[9] C. C. Taylor, Temperature, Growth, and Mortality ,The Pacific Cockle, ICES J. Mar. Sci., vol. 26, no. 1, pp. 117-124,(1960).

[10] D. A. Pauly, Selection of simple methods for the assessment of tropical fish stock, FAO Fish Cire, vol. 729, p. 54 (1984).

[11] L. Laubier, Exploitation et surexploitation des ressources marines vivantes. Ed. Tec \& doc, (2003).

[12] J. A. Gulland, The fish resources of the ocean. West Byfleet, Surrey, Fish. News Books Ltd FAO, vol. 255, (1971).

[13] D. Pauly, Quelques méthodes simples pour l'estimation des stocks de poissons tropicaux, FAO Doc Tech Pêch., vol. 234, p. 56p, (1985).

[14] D. Pauly, On the sex of fish and the gender of scientists: a collection of essays in fisheries science, vol. 14. Springer Science \& Business Media, (1994).

[15] S. Boufersaoui et M. Bedda, Croissance et exploitation de deux espèces de poissons plats pleuronectiformes des eaux algériennes: Citharus linguatula (Linnaeus, 1758) et Dicologlossa cuneata (Moreau, 1881). Université Houari Boumediene - Ingéniorat d'état, (2009).

[16] P. Sparre and S. C. Venema, Introduction à l'évaluation des stocks de poissons tropicaux: Manuel. Food \& Agriculture Org., (1996).

[17] D. Pauly and M. L. Soriano, Some practical extensions to Beverton and Holt's relative yield-perrecruit model, in The first Asian fisheries forum, $p$. 491-496, (1986).

[18] R. Toujani and M. M. Kraiem, Dynamique de la population de sandre Stizostedion lucioperca (L., 1758 pisces, percidae) dans la retenue du barrage de Sidi Salem, Bull Inst Natn Scien Tech Mer Salammbô, vol. 29, (2002).

[19] A. Bouamra, Etude de la croissance du sandre, Sander lucioperca (Linnaeus, 1758), dans trois systèmes lacustres Algériens (W. Ain Defla, Boumerdès et Skikda), Mémoire de Magister, Université des Sciences et de la Technologie Houari Boumediene, 54 p, (2011).

[20] F. Bilgin, M. Cilbiz, R. Uysal and M. Ceylan, Length Based Stock Assessment of Pikeperch (Sander lucioperca, Linnaeus, 1758) with TropfishR in Karataş Lake (Burdur-Turkey), (2019).

[21] S. Abdolmalaki and I. Psuty. The effects of stock enhancement of pikeperch (Sander lucioperca) in Iranian coastal waters of the Caspian Sea. ICES Journal of Marine Science, 64: 973-980, (2007). 
[22] K. O. Fayçal, Contribution à l'étude de la dynamique du sandre (Sander lucioperca Linnaeus, 1758) dans le barrage de Ghrib. Université Djilali Bounaama de Khemis Miliana Faculté : Sciences de la nature et de la vie et sciences de la terre, (2015).

[23] E. Kokkonen, O. Heikinheimo, Z. PekcanHekim, and A. Vainikka, Effects of water temperature and pikeperch (Sander lucioperca) abundance on the stock-recruitment relationship of Eurasian perch (Perca fluviatilis) in the northern Baltic Sea, Hydrobiologia, vol. 841, no. 1, pp. 7994, (2019).

[24] E. Yongo and N. Outa, Growth and population parameters of Nile tilapia, Oreochromis niloticus (L.) in the open waters of Lake Victoria, Kenya, Lakes Reserv. Sci. Policy Manag. Sustain. Use, vol. 21, no. 4, pp. 375-379, (2016).

[25] İ. Balik, H. Çubuk, B. Karaşahin, R. Özkök, R. Uysal, and A. Alp, Food and Feeding Habits of the Pikeperch, Sander lucioperca (Linnaeus, 1758), Population from Lake Eğirdir (Turkey), Turk. J. Zool., vol. 30, no. 1, pp. 19-26, (2006).

[26] J. P. Gröger, H. Winkler, and R. A. Rountree, Population dynamics of pikeperch (Sander lucioperca) and its linkage to fishery driven and climatic influences in a southern Baltic lagoon of the Darss-Zingst Bodden Chain, Fish. Res., vol. 84, no. 2, pp. 189-201, (2007).

[27] O. Heikinheimo, Z. Pekcan-Hekim, and J. Raitaniemi, Spawning stock-recruitment relationship in pikeperch Sander lucioperca (L.) in the Baltic Sea, with temperature as an environmental effect, Fish. Res., vol. 155, pp. 1-9, (2014).

[28] M. B. Danilov, E. A. Kriksunov, A. E. Bobyrev, A. D. Sheremet'ev, M. M. Mel'nik, and S. O. Severin, Dynamics of the Sander lucioperca Population in Lake Peipsi-Pihkva, J. Ichthyol., vol. 58, no. 4, pp. 531-544, (2018).

[29] J. P. Barry and M. J. Tegner, Inferring Demographic Processes from Size-Frequency Distributions: Simple Models Indicate Specific Patterns of Growth and Mortality, Fish Bull, vol. 88, pp. 13-19, (1989).

[30] D. Lederoun, A. Chikou, E. Vreven, J. Snoeks, and M. P. Vandewalle, Population parameters and exploitation rate of Sarotherodon melanotheron melanotheron rüppell, 1852 (Cichlidae) in Lake Toho, Benin, J. Bio. \& Env. Sci. Vol. 6, No. 2, p. 259-271, (2015).

[31] R. Toujani, H. Missaoui, and M. S. Romdhane, Cycle sexuel des femelles de sandre Stizostedion lucioperca (L., 1758) Pisces, Percidae) dans la retenue du barrage de Sidi salem Tunisie,
Bull. Inst. Natn. Scien. Tech. Mer de Salammbó, Vol. 27, (2000).

[32] M. Mhetli, Le sandre Stizostedion lucioperca (Linnaeus, 1758) téléostéen percidae. Allochtone: étude biologique et essai d'optimisation des critères d'élevage, Thèse de Doctorat, Université de Tunis, 173 p, (2001). 